ported cures in the public journals afford. In answer, I could speak of forced extension five times repeated, and unavailing at last, but productive of high constitutional derangement; of erysipelas succeeding a similar attempt, and of the rapid recontraction of the limb; of dormant disease roused with such activity, that thoughts of amputation came uppermost in the surgeon's mind. Such dangers cannot be ignored; they perplex and distress the surgeon; and I feel strongly that any plan, which offers some security against their occurrence, is worthy of the support and consideration of the profession.

\section{PLASTIC OPERATION FOR THE RELIEF OF STRUCTURAL CONTRACTION FROM A BURN.}

By Albert G. Walter, Surgeon, Pittsburgh, Pennsylvania.

Auongst the many established surgical operations, there are i'w which are more gratifying in their results or less hazardous in their consequences, and which yet have contributed more to advance surgery to its present pre-eminence, than plastic operations, and those for the relief of deformities in general ; for we find that, in the execution of the various operative proceedings belonging to that department, artistical skill and ingenuity have necessarily become handmaids to the accomplished surgeon.

A narrative of the following case, from the high degree of deformity, the tender age of the patient, the extent of the incisions necessary for remedying the contraction, and its successful result, will not fail to be interesting to the professional reader.

Mary, daughter of Henry Hainz, of Sharpsburg, Alleghany County, Pennsylvania, aged six years, was placed under my care for the relief of a most distressing deformity, resulting from the effects of a severe burn received some eighteen months ago. 'The following history of the case was given me. In the absence of her mother she was playing before the fire, when her clothe's ignited, and before assistance could be had, or the burning garments extinguished, the whole face, fore part of the neck, and breast were deeply burnt. Sloughing ensued, followed by suppuration and slow cicatrisation, which, after a period of six months, was completed. No mechanical means to prevent contraction having been employed, the neck shortened upon itself in front, giving to the face a most unsightly appearance.

When she was brought to me, the front part of the neck was occupied by a firm callous cicatrix, running in bridges from the chin and entire edge of the lower maxilla to the sternum, and so confining the parts, that the distance or space from point of chin to sternum was less than an inch. The head being thus firmly bound down to the sternum, any rotation of the neck was prevented; the angles of the mouth and lower eyelids were drawn down; the lower lip was everted; the mouth constantly open, causing dryness of the fauces during sleep, and continued rest lessness. The alveolar process of the incisor teeth had yielded to the constant strain, everting it, and giving the teeth, thickly coated with tartar, an outward direction. Saliva was secreted, profusely wetting and chafing the neck and breasts. As mastication could not be performed, the child had subsisted on milk and other nutritious liquids. Though pale and emaciated, her general health had been good. Having decided on attempting relief by dividing the cicatrix through its whole extent, and on transplantation, on January 12th, 1854, in presence of Drs. Reynolds, Murdoch, and several others, the patient being fully under the influence of chloroform, I made a transverse incision, commencing on one side of the neck a little below the angle of the lower jaw, and carried forward to the other side, terminating at a point opposite to where it was commenced, care being taken that the terminal ends of the incision should be in healthy sicin. The cicatrix being thus completely severed, the platysma myoides, being found contracted, was divided to the same extent in the line of the first incision, together with a layer of fatty substance, which was found shortened and thickened by fibrous bands stretching across it; there was very little bleeding, and of a venons character. The sternal portions of both sterno-cleido-mastoid muscles were shortened, and had to be divided. The head now liberated assumed its natural position; the jaws could be closed, though the incisors did not meet. An open wound, five inches in a vertical and seven in a horizontal direction, was left to be filled up by a flap of slin borrowed from the right shoulder and upper arms for this purpose. From the right angle of the wound in the neck the knife was entered and carried down and forwards in a curve over the shoulder and external surface of the upper arm to near the elbow, thence returning upwards along the posterior face of the arm and shoulder to behind and below the first incision, leaving a pedicle of over three inches as the matrix for subsequent nourishment of the flap. By short and rapid strokes of the knife, the skin circumscribed by these incisions, together with its layer of cellular tissue, was separated from the fascia from below upwards, thus entirely denuding the upper arm and shoulder. The fiap was purposely made much larger than the space to be filled up by it required, in order that union by first intention might not be prevented by the inherent power in transplanted skin of contraction upon itself, and which is so likely to occur where the thap is too limited, as well as to allow for any sloughing that might ensue. Notwithstanding the extent of round, tise loss of blood was inconsiderable. All oozing of blood having ceased. the flap, twisted at its pedicle, was placed in its new positıon in front of the neck, and secured by several interrupted sutures and Carlshad needles; the spaces between them were carefully brought together by narrow stripes of adhesive plaster, surroundin the neck, and making gentle pressure, approximating the transplanted skin to the bottom of the wound and its edges, thus facilitating the early and free inosculation of the minute blood-vessels, and speedy intervention of that alhesive inflammation, without which a successful result could not be obtained. The wound on the shoulder and arm was treated with warm water dressing; the head was thrown back, and retained in that position by a small bolster placed between the occiput and shoulders, and by a bandage. The patient was placed resting on her back, and compresses wrung ont of a warm infusion of camomile flowers were kent upon the front of the neck to aid by genial warmth, the circulation and vitality of the flap, and promote its adhesion.

To effect this was, during the first day after the operation, exceedingly difficult, f:om frequent romitings that ensued, consequent on the inhaled chloroform; and much anxiety for the safety of the flap was occasioned by rather free bleeding from a vein over the trachea which took place, and which would necessarily have prevented adhesion, and been followed by suppuration or sloughing. To avoid this, some of the stitches were cut out, and the coagulated blood removed. All bleeding loving flap was again laid down, and confined by stripes of adhesive plaister. No further bleeding after the first twenty-four hours having occurred, and the vomiting having coased, the condition of the patient became more farourable. Very little fluid nourishment, given in teaspoonfuls only, was allowed, and every care was taken to guard agains spealing; sleep and quietude beng secured by sulphate of morphia, in one-sixteenth grain doses at intervals of two or three hours, or as occasion required, to allay the restlessness which not only the wound but the position occasioned. The protracted posture of the patient on her back for some days was very irksome and uncomfortable; the craving for food and drinks was distressingly urgent; reaction was moderate.

On the fourth day after the operation, adhesion having taken place in the greater extent of the wound, six sutures and needles were removed; and over the neck and arm light linseed-meal poultices were substituted for the water-dressinga. The adhesions were earlier and firmer on the right side; towards the point of the flap, they were slow in forming, and less firm. A small portion below the skin sloughed, from ail. hesion failing to take place between that jart of the new flap and the old cicatrix. Suppuration, however, eventually closed the wound; the last suture was removed on the tenth day, when the wound had nearly closed. The shoulder and arm duly suppurated and rranulated; milk and broth in teaspoonsful, given frequently, being the only nourishment allowed.

Two weeks after the operation, the flap was completely adlerent, excent below the skin, where the part was bein. filled up by granulation, which, a reek later, was completed. The patient was now permitted to change her position; and, owing to the pale and flabby condition of the granulations on the arm and snouiders, and her feeblo constitutional power: wine and sslid tood were substituted for the liquid diet.

After another wetk, all functions being normal, and the wound of shoulder healing kindly, she left her bed. Two months later, this too had closed, and the girl was restored to her natural condition; the head was erect and moveable, with well formed neck; har jaws approximated, and the lips wer. closed; the features were completely freed from that distressing expression which she lad presented before. 
I have seen my little patient frequently since. She is in excellent health, and I feel certain that no one would suspect the former deformity. But for the cicatrix of the burn on the face and front of the chest, no mark of her former disfigurement remains.

REMniкs. Success in cases like the foregoing cannot fail to force the attentive surgeon to a still more close and watchful study of Nature's inexhaustible resources, and to convince him that, though justly proud of his present healing and restoring powers, there is much yet to be done, and much, too, to be acquired, before resting satisfied, from the study of that great book of Nature, and, in closing its pages, he may consider his mission accomplished, and Nature's teachings exhausted.

\section{Cransactions of 迮uamethes.}

\section{BATH AND BRISTOL BRANCH.}

CASE OF INTUSSUSCEPTION: SURVIVING FIVE MONTHS.

By Augustin Prichard, Esq., Surgeon, Bristol.

[Read Fcbruary 25th, 1858.]

ON Mionday, August 3rd, 1857, a healthy little boy, six years and a half old, was suddenly seized with intense pain in the umbilicus while playing with his brothers in a field near Clifton. An old nurse who was with him told him to press himself against the stile, by which he obtained some relief.

When he arrived home, he was given a little tincture of rhubarb, and two grains of calomel; and his bowels were moved the next day.

August 5th. I saw him, and found him sick and restless, with a little occasional wandering in his talk; but, as I had frequently attended him with slight feverish colds and other infantile disorders, when he showed similar symptoms, I took no very special notice of them, and ordered him some salines to relieve his fever. 'The next day he was worse, and complained of great pain in the abdomen. The bowels had not been open, and no flatus had passed per anum. I ordered him a dose of castor oil, with two minims of laudanum.

August 7th. He was still restless. The bowels had not acted, and two injections had been administered with no result. He was given four drops of laudanum.

August 8th. He was weak and collapsed. He had taken no nourishment whatever since Monday, and his bowels had not been open since the Tuesday. He had been sick once or twice; but he had taken three doses of castor oil, none of which had returned; and he had also had three injections of castor oil and turpentine with laudanum, in gruel, which had remained, but were ineffectual. From this date, I had the advantage of Dr. Symonds's aid in the subsequent treatment of this unpromising case. We gave him a copious injection of warm water while in the bath, which he resisted with the utmost violence, and screamed as if he suffered the greates pain. A large quantity of water was thrown up, and returned without any frecal matter. He was then ordered a blister on the upper part of the back, under the idea that possibly some paralytic condition of the nerves of the intestines might be present; and, as he was delirious and sinking, he was to have some beef-tea and wine injections during the night.

August 9th. A small quantity of fæcal matter followed the injections of beef-tea and wine, and he recovered a little, but was still delirious and extremely weak, complaining of soreness, and unwilling to swallow anything.

In this state he continued nearly a week, taking a little milk, becoming gradually thinner, and wandering a good deal in his talk. His bowels were not only open, but there was a tendency to diarrhoea; and his mouth and throat became very aphthous. On the 20th-that is, fifteen days after his attack -he passed a portion of alimentary canal, perhaps rather more than a square inch in size; and he was getting excessively thin and weak. He complained for some days of great pain in passing water, and his urine became ammoniacal and fotid. Bubbles of gas came out from the urethra, and he screamed out that something hard was coming; and, in fact, it was soon apparent that fluid fecal matter was passing through the bladder. He was ordered some port wine and laudanum occasionally, what nourishment he could take, and a drachm of cod-liver oil twice daily.
August 22nd. He was taken again with sudden and intense pain in the abdomen, with restlessness, delirium, and sinking and, in the latter part of the day, he passed another long shred of tissue, apparently not only mucous membrane, but some loose cellular membrane with it. The next day we in creased his wine, and he passed the third portion of tissue and from this time he he mended a little, and continued to take three drachms of port wine every three hours, with occa siongl doses of laudanum and cod-liver oil; and the next week he took some nourishment; whilst, at the same time, he had much bubbling and pain when he passed water, and he was constantly pulling at his penis. During the ensuing fortnight, he went on much in the same way, taking an ounce of wine with sugar every three hours, and nothing else. The wine discharge of the contents of the intestine through the urethra. His emaciation was so great that the integuments and muscles of the abdomen became so thin a layer as to show the vermi cular or peristaltic action of the intestines; and this phenomenon, which I had never witnessed before, was sufficiently distinct to enable us to say that the intestines moved freely, and that there had been no general peritonitis producing adhesions. His shrieks, when he passed water, were most distressing.

September 14th. He was evidently sinking. He lay without taking any notice, except when roused, and then he became fretful; and it appeared impossible to move him without causing his integuments, which appeared simply strained ove his skeleton, to give way. Pulse 140, scarcely perceptible. His extremities were cold, and he appeared moribund; and in the evening I left him, not expecting to find him alive in the morning.

September 15th. I found him slightly revived, having sweated much in the night. He began to take a little milk and other nourishment, and from this time he improved. The urine was occasionally tinged with fæcal matter, and I discovered muscular fibres in the débris, apparently from some broth that had been given him. Now and then, for twentyfour hours, no gas escuped from the bladder; and this appeared to be the case when the contents of the alimentary canal were more solid.

September 25th. He was still better; that is, his tongue was clean, and his appetite improved. The urinary difficulty remained. $\mathrm{He}$ was conscious of the passage of the air and other matters into the bladder, for it was generally accompa nied with a peculiar gurgling or bubbling sound, audible to exe one round; and he screamed excessively when it occurred. He then would cry out, "Oh! it's blowed"; and afterwards the bubbles were found issuing with the urin from the urethra. He passed urine always in a cloth, as he was too thin and weak to be raised; and, when he was shown the stains of fæcal matter upon the napkins into which he had just made water, he said, "Oh! that's what comes when it's blowed."

He was at this time taking ten drachms of port wine every three hours, with four minims of laudanum at night, and occa sionally by day; and gradually his appetite and strength im proved, but he did not perceptibly gain flesh. Since the first week of his illness, his evacuations had been of a slate colour, without the slightest tinge of bile; and they have also had a slimy and greasy feel to the finger.

In the middle of October, he had another sudden attack of pain at the umbilicus, almost as severe as the first; but it soon subsided under the use of opiates, and without any distinct evidence of fresh intussusception, and he returned to his usual state; that is, some muscular power, fair appetite, with the most remarkable emaciation. At une period he ate as much as three mutton chops a day, besides taking cod-liver oil and milk, and nearly half a bottle of port wine, in the twenty four hours; and still not a particle of adipose tissue could be discovered about him

October 18th. The bubbling of the urine ceased, and there was never again any evidence of communication between the intestines and bladder. He became stronger, so as to be able to sit up in bed, but not to stand. His urine became clear.

He was constantly tried with doses of quinine and acids, and different kinds of tonics, but without avail. The remedies that seemed to do most towards strengthening him were nux vomica and oxgall in a pill. He never showed any sign that any fat was assimilated, and he never showed any indication of the presence of bile either in his evacuations or in his skin and yet he took milk, and other articles of diet which usually fatten children. The fæcal matter was generally of the same 